renowned for producing great scholars has reached the heights of scientific achievement. His life is full of lucky turns. $\mathrm{He}$ could have easily ended up as a scholar of Urdu or Persian; or worse still, grazing in the offices of the Indian civil service, on which his father was very keen. On his return from Cambridge, after finishing his doctorate, he could well have disappeared into the anonymity of the colonially inherited educational institutions of Pakistan. But fortune was on his side and he escaped.

Perhaps fortune has little to do with it. It is Salam's hard work and remarkable intelligence that eventually brought him the Nobel Prize (awarded in 1979 for his work on the theory of electro-weak force). Or perhaps it is his sincerity of purpose and deep humility combined with a love for beauty and learning that is the driving force behind his achievements. Whatever the reason, Salam could not have overcome his own lugubrious nature without deep faith. Over the years, as this book shows so convincingly, his faith in science as the ultimate pursuit of objective truth, and his belief in Islam as the world-view of compassion, have increased not diminished.

Salam has achieved a remarkable, personal synthesis of Western science and Islam. It manifests itself in all that he preaches and in his own work. His involvement with symmetries in physics, he has said, stems from

my Islamic heritage for that is the way we consider the universe created by God, with ideas of beauty and symmetry and harmony, with regularity and without chaos. The Koran places a lot of emphasis on natural law. Thus Islam plays a large role in my view of science; we are trying to discover what the Lord thought . . .

The fact that Salam was looking for unity in seemingly disparate forces of nature is considered by him to be part of his faith both as a physicist and a Muslim. In more than one essay, he quotes from the verse of the Qur'an that reads:

Thou seest not, in the creation of the AllMerciful, any imperfection

Return thy gaze, seest thou any flow

Then return thy gaze, again and again

Thy gaze comes back to thee dazzled, aweary.

This is the faith of all physicists, Salam tells us. The deeper we seek the more is our wonder excited, the more is the dazzlement of our gaze.

Ideals and Realities provides a revealing insight into the mind of Abdus Salam. There is a great deal here that one can disagree with, argue against, even dismiss as too simplistic. But one cannot help being moved by Salam's compassion and conviction, his strong faith in science and in his religion, his concern for the developing countries, and by the facility with which he hatches one bright idea after another. My only hope is that his melancholy outlook is not contagious.

Ziauddin Sardar is Director of the Center for Policy and Future Studies at East-West University, Chicago.

\section{Keeping the gates}

Philip H. Abelson

How to Edit a Scientific Journal.

By Claude T. Bishop.

ISI Press: 1984. Pp.138. Hbk \$21.95; pbk $\$ 14.95$.

To YOUNG scientists and others not well established, editors and their associated apparatus represent a fearsome and mysterious barrier to recognition and advancement. The continuing emphasis on publish or perish has enlarged the importance of the role of editors in decisions to accept or reject manuscripts. Hence, there should be a broad audience for a book that enables readers to look behind the scenes at the machinery that influences the fate of millions of scientists and the expenditure of billions of dollars. In addition, those scientists who are or may become part of the editorial machinery will find Dr Bishop's book helpful as a source of ideas and guidance about all phases of the editing of scientific journals.

The author brings to bear some 18 years of experience in editorial matters. For a number of years, he was editor of the Canadian Journal of Chemistry. Since then, he has had responsibility for 12 journals published by the National Research Council of Canada. These publications have circulations of 1,200 to 6,000 , figures typical of most journals today. $\mathrm{Dr}$ Bishop's writing reflects his years of experience; that is, he seems conditioned to the problems faced by small journals with limited financial resources. Nevertheless, much of what he states is applicable to scientific journals of all kinds.

Discussion of the peer review system is especially good. In journals large and small the crucial factor in achieving good quality is the reviewing process. As Bishop points out, "All editors, and most authors, will affirm that there is hardly a paper published that has not been improved, often substantially, by the revisions suggested by referees"'. He further points out that,

One function of the refereeing system that is often overlooked is its indirect influence on the initial preparation of a paper. Established scientists write their papers with a critical sense that anticipates referees' questions. Without this subtle pressure in the background, there can be little doubt that the quality of presentation would deteriorate along with the content.

Because of the publish-or-perish syndrome, a minority of authors advocate abandoning the reviewing process altogether. They "regard all referees and editors as biased adversaries whose objectives are solely to reject, delay, or scoop all papers submitted to them". Bishop denies the validity of such views, stating that the common experience of editors is that "examples of intentional delay, biased reports, or unethical behaviour are extremely rare"'. It is, of course, one of the important functions of editors to review the referees' reports to guard against delay or bias and to investigate allegations that material in a paper has been stolen.

The matter of ethics in the field of scientific publications has become of increasing concern. Furthermore, it is a matter on which editors have primary responsibility. Bishop devotes a chapter to the topic, pointing out that questions of ethics have been present throughout the history of scientific journals. However, scientists today are under enormous pressure to expand their bibliographies and a few cases of plagiarism and fraud have been uncovered. While calling attention to the situation, Bishop adopts a sensible view on the matter of reporting fraudulent results, he notes that if the work is insignificant, the experiments may not be repeated nor will the paper necessarily mislead others; and if the claims in the paper are significant, the work will surely be repeated and its worthlessness exposed.

In the book the role of the editor is rather narrowly defined. Emphasis is on procedures to select and improve the manuscripts that are voluntarily submitted. But the active frontiers of science keep changing, and unless the content of a journal evolves it will become obsolescent and new publications will be created to fill the gap. It should be the responsibility of the editor to be alert to changes and if necessary to recruit manuscripts dealing with emerging areas related to the current content of the publication. The editor's flexibility is often limited by financial or political considerations. Thus if the editor is to be truly effective, he or she must be more than a custodian of manuscripts. Editors must be aware of - and participate in - decisions that affect their ability to produce a firstrate journal.

Although the basic processes of peer review and editorial decisions concerning manuscripts remain unchanged, the major journals in the United States have been modernizing their mechanism for accomplishing these procedures. They are incorporating the use of electronic devices - a matter that is barely touched on in this volume. Computer-assisted manuscript tracking and monitoring of reviewers' performance has been widely adopted, diminishing routine clerical tasks and improving selection of referees. The application of computer word-processing is beginning to transform the mode of transmittal of material from authors to editors. Already some manuscripts are being transmitted by diskette and ultimately the material will flow to the editor and to reviewers by computer networks.

However, though some of the mechanisms of editing may change, the basic relationships of authors and editors will remain largely the same. Bishop's book will continue to be a useful guide to authors and would-be editors.

Philip H. Abelson is Editor of Science. 